\title{
Graft Copolymerization of Styrene from Poly(vinyl alcohol) via RAFT Process
}

\author{
Gholam Ali Koohmareh, Morteza Hajian, and Hazhir Fallahi \\ Department of Chemistry, College of Science, University of Isfahan, Isfahan 81746-73441, Iran \\ Correspondence should be addressed to Gholam Ali Koohmareh, g.a.koohmareh@sci.ui.ac.ir
}

Received 16 March 2011; Accepted 9 June 2011

Academic Editor: Jose Ramon Leiza

Copyright ( $) 2011$ Gholam Ali Koohmareh et al. This is an open access article distributed under the Creative Commons Attribution License, which permits unrestricted use, distribution, and reproduction in any medium, provided the original work is properly cited.

\begin{abstract}
Polystyrene, PS, was grafted from poly(vinyl alcohol), PVA, backbone by reversible addition-fragmentation chain transfer (RAFT) polymerization. The hydroxyl groups of the PVA were converted into aromatic dithioester RAFT agent and polymerization began in the presence of this agent. The structure of compounds was confirmed by FT-IR and ${ }^{1}$ HNMR spectroscopy. The graft copolymer was characterized by thermogravimetric analysis (TGA), X-ray diffraction (XRD), and scanning electron microscopy (SEM). Grafted polystyrene chains were cleaved from the PVA backbone by acidic hydrolysis of the PVA-g-PS, and its polydispersity index, PDI, was determined by gel permeation chromatography (GPC) showing narrow molecular weight distribution.
\end{abstract}

\section{Introduction}

Poly(vinyl alcohol) (PVA) has excellent film forming, emulsifying, and adhesive properties. It is odorless, nontoxic and has high tensile strength and flexibility as well as high oxygen and aroma barrier properties. PVA is a water-soluble semicrystalline polymer with good chemical and thermal stability and has biomedical applications [1-4]. Functionalized modification of PVA at the side groups is easy by utilizing various reactions of hydroxyl groups with small molecules or polymers. Such modification may provide PVA with pendant functional groups or graft polymer chains, and thus expand their applications in biological fields [5-8]. There are plenty of hydroxyl groups present as side groups on the backbone chain of poly(vinyl alcohol). The hydroxyl groups bring about good solubility in water but, on the other hand, lead to its high resistance to oil and poor mechanical properties. Because the modified PVA possesses hydrophilic backbone chain and hydrophobic branched chains synchronously after being modified by vinyl monomers, it can serve as amphiphilic compatibility-reagent between a hydrophobic polymer and a hydrophilic polymer. Graft copolymerization is one of the most important methods to modify PVA [9].

The synthesis of polymers with predetermined molecular weight and low polydispersity index can possible with controlled free-radical polymerization techniques, such as nitroxide-mediated polymerization (NMP), [10] atom transfer radical polymerization (ATRP), [11] and reversible addition fragmentation chain transfer (RAFT) polymerization [12-15] for a great variety of vinyl polymers. The last one, (RAFT), is one of the promising living radical methods for synthesizing well-defined graft polymers. A wide range of monomers can be polymerized in a controlled manner under nondemanding reaction conditions via this technique. When grafted and free polymers mediated by the same RAFT agent, the molecular weights and molecular weight distributions of the grafted and the free polymer should be very similar [16].

There are many reports about grafting polystyrene to polyvinyl alcohol [17-22]. However, the molecular weight and molecular weight distribution of the grafts was not controlled.

Here, graft copolymerization of styrene from poly(vinyl alcohol) by modifying it with a dithioester RAFT agent was investigated.

\section{Experimental Section}

2.1. Materials and Instruments. All solvents, monomer, and most chemicals were purchased from Merck-Chemical at 
the highest purity available unless otherwise stated. Styrene $(99 \%)$, was purified by washing with an aqueous solution of $\mathrm{NaOH}(5 \mathrm{wt} \%)$ to remove the inhibitor, followed by distilled water until the washings were neutral to litmus, dried by anhydrous $\mathrm{MgSO}_{4}$ and fractionally distilled under vacuum. 2,2'-Azobis(isobutyronitrile) (AIBN, 97\%) was purified by recrystallization from methanol and dried at room temperature in a vacuum oven and finally, stored at $-15^{\circ} \mathrm{C}$. Dimethylacetamide (DMAc), tetrahydrofuran (THF), triethylamine (TEA), acetone, 1-Bromonaphtalene, and carbon disulfide and toluene were dried over molecular sieves $(4 \AA)$ before use. Poly(vinyl alcohol) (PVA, AppliChem, $72000 \mathrm{~g} \mathrm{~mol}^{-1}$, DP $=1600,98 \%)$, 2-Chloro-2-phenylacetyl chloride (CPAC, $90 \%$ ) were used as received. THF was completely dried by sodium press method.

FTIR spectra were recorded on a JASCO FTIR-6300 spectrometer by using $\mathrm{KBr}$ pellets. ThermoGravimetric analysis (TGA) and differential scanning calorimetry (DSC) were performed on a Mettler TG5 system under nitrogen atmosphere at a heating rate of $10^{\circ} \mathrm{C} / \mathrm{min}$. NMR spectra were recorded on Bruker Avance $400 \mathrm{MHz}$ spectrometer. Molecular weights were determined using Knauer Gel permeation chromatography (GPC) equipped with Smartine Pump 1000, a differential refractive index (DRI) detector (Smartin Ri 2300) and PL Gel $10 \mu \mathrm{m}$ column. THF was used as solvent with flow rate of $1 \mathrm{ml} / \mathrm{min}$ at room stemperature. GPC was calibrated with standard polystyrene with polydispersity index of 1.09 . The elemental analysis was carried out by a Leco, CHNS932. X-ray diffractions were performed on Bruker D8 Avance instrument. Scanning electron microscopy (SEM, AIS-2100 Model-550-SERON Technology) was used to analyze the morphology of the polymers. The samples were gold-coated and operated at an accelerating voltage of $20 \mathrm{kV}$.

2.2. Esterification of Poly(vinyl alcohol) Using 2-Chloro2phenylacetyl Chloride (CPAC); (PVA-Cl). $0.5 \mathrm{~g}$ of PVA $(1.09 \times$ $10^{-2}$ mol hydroxyl groups) was dissolved into a three-neck round-bottom flask, containing dry DMAc $(12 \mathrm{ml})$ and an excess of triethylamine $\left(4.4 \mathrm{~g}, 4.36 \times 10^{-2} \mathrm{~mol}\right)$, which used as proton scavenger. CPAC $\left(4.1 \mathrm{~g}, 2.18 \times 10^{-2} \mathrm{~mol}\right)$ was finally added dropwise at $0^{\circ} \mathrm{C}$ during $3 \mathrm{~h}$ to the flask under dry $\mathrm{N}_{2}$ atmosphere. The solution was stirred overnight at $60^{\circ} \mathrm{C}$. The organic solution was then washed several times with an aqueous solution of $\mathrm{NaHCO}_{3}$ and distilled water to complete removal of any unreacted $\mathrm{CPAC}$ and $\mathrm{Et}_{3} \mathrm{NH}^{+} \mathrm{Cl}^{-}$salt and dried over $\mathrm{MgSO}_{4}$ for $12 \mathrm{~h}$. The functionalized polymer was precipitated in hexane. Finally, yellowish product was placed in a vacuum oven at $50^{\circ} \mathrm{C}$ to dry overnight; (PVA-Cl). Weight of dry PVA- $\mathrm{Cl}=1.73 \mathrm{~g}$; mass increase due to esterification $=$ $1.23 \mathrm{~g} ; \%$ mass increase $=246 \%$.

2.3. Synthesis of RAFT Agent onto Poly(vinyl alcohol); (PVA$R A F T)$. A solution of 1-bromonaphtalene $(0.32 \mathrm{~g}, 1.5 \times$ $\left.10^{-3} \mathrm{~mol}\right)$ in anhydrous THF $(6 \mathrm{ml})$, was added dropwise under nitrogen to a dried two-neck round-bottom containing magnesium $\left(0.042 \mathrm{~g}, 1.3 \times 10^{-3} \mathrm{~mol}\right)$ and $20 \mathrm{ml}$ anhydrous THF within $1 \mathrm{~h}$ and refluxed for $3 \mathrm{~h}$. An excess of carbon disulfide $\left(0.165 \mathrm{~g}, 1.9 \times 10^{-3} \mathrm{~mol}\right)$ was then added dropwise to the flask at room temperature. The reaction mixture was heated to $40^{\circ} \mathrm{C}$ for $3 \mathrm{~h}$. The resultant brown solution was then transferred to another flask containing PVA-Cl $\left(0.1 \mathrm{~g}, 0.61 \times 10^{-3} \mathrm{~mol}\right)$ dissolved in THF $(25 \mathrm{ml})$ and refluxed for $24 \mathrm{~h}$. After cooling, methanol $(50 \mathrm{ml})$ was added and the resulting orange precipitate was washed with methanol and then oven-dried under vacuum at $60^{\circ} \mathrm{C}$; (PVA-RAFT).

Weight of dry PVA-RAFT $=0.22 \mathrm{~g}$; mass increase due to second dramatization $=0.12 \mathrm{~g} ; \%$ mass increase $=120 \%$.

CHNS (Found): C (41.21\%), H (4.8\%), N (0\%), and S $(11.17 \%)$.

2.4. Graft Copolymerization by RAFT Process. The PVARAFT sample $\left(0.21 \mathrm{~g}, 0.4 \times 10^{-3} \mathrm{~mol}\right)$ was pretreated with dry toluene in a round-bottomed flask for $24 \mathrm{~h}$ to obtain a homogeneous mixture. Monomer (styrene, $23.3 \mathrm{ml}, 0.2 \mathrm{~mol}$ ) and initiator (AIBN, $0.0067 \mathrm{~g}, 0.4 \times 10^{-4} \mathrm{~mol}$ ) dissolved in $18 \mathrm{ml}$ toluene were then added into flask. Polymerization performed in solvent $(50 \%(\mathrm{v} / \mathrm{v})$ to monomer). The flask was subsequently capped with rubber septa and deoxygenated through purging with nitrogen for $20 \mathrm{~min}$ and placed immediately in a preheated oil bath at $60^{\circ} \mathrm{C}$. The reaction was stopped after $48 \mathrm{~h}$, by cooling the reaction flask in an icewater bath. The mixture was then poured into excess methanol to precipitate the polymer. The precipitate was filtered and dried to a constant weight under vacuum at $60^{\circ} \mathrm{C}$. The crude PVA-g-PS sample was thereafter repeatedly washed with THF to remove any unreacted RAFT agent. Then, the homopolymer of styrene was removed completely from the graft copolymer by exhaustive Soxhlet extraction with toluene for 2 days at $120^{\circ} \mathrm{C}$. The final graft copolymer was dried to a constant weight under vacuum at $60^{\circ} \mathrm{C}$. The grafting ratio $=36 \%$.

2.5. Cleaving of PS from PVA Backbone. PS chains were cleaved from the PVA surface under acidic conditions. $0.12 \mathrm{~g}$ of grafted PVA (36 wt\% graft ratio) sample was immersed into a round-bottomed flask and an equal portion of $37 \%$ $\mathrm{HCl}$ was added to the reaction medium and the mixture was diluted with THF to be $25 \%$ in $\mathrm{HCl}$. The mixture was refluxed for 2 weeks until the grafted PVA was completely hydrolyzed, leading to a homogeneous brown solution. The reaction mixture was filtered, and the solvent (THF) in the filtrate was evaporated off using a rotary evaporator and, finally, dried at $50^{\circ} \mathrm{C}$ in a vacuum oven. The resulting viscous liquid was dissolved in dichloromethane and then extracted twice with distilled water. The organic phase was dried under anhydrous $\mathrm{Na}_{2} \mathrm{SO}_{4}$ overnight. After filtration, PS was collected by complete evaporation of the solvent. The highly viscous PS product was precipitated in methanol washed several times with methanol, then dried and dissolved in THF and analyzed by GPC. The weight-average molecular weight of the cleaved PS of above-mentioned sample was $26000 \mathrm{gmol}^{-1}$.

\section{Results and Discussion}

First, poly(vinyl alcohol) was converted to PVA-Cl via an esterification reaction by using 2-chloro-2-phenylacetyl 

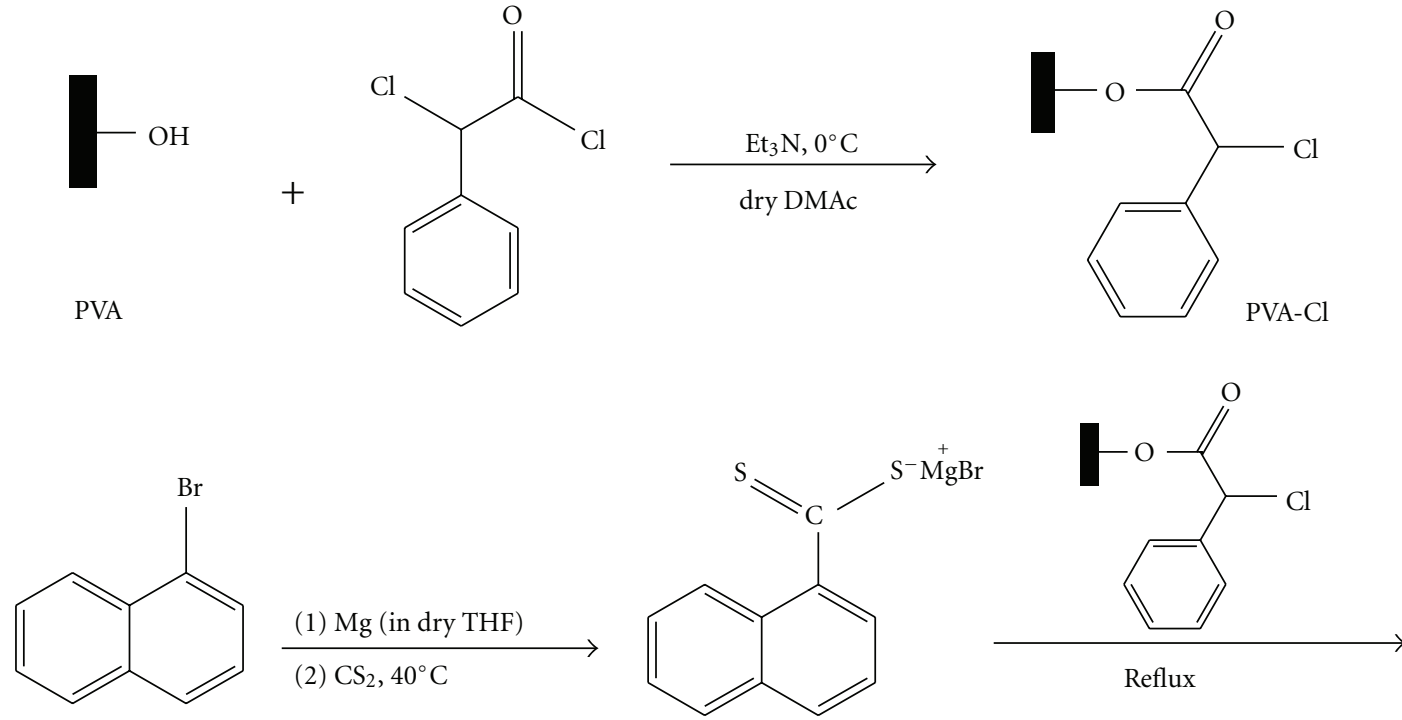<smiles>COC(=O)C(SC(=S)c1cccc2ccccc12)c1ccccc1</smiles>

PVA-RAFT

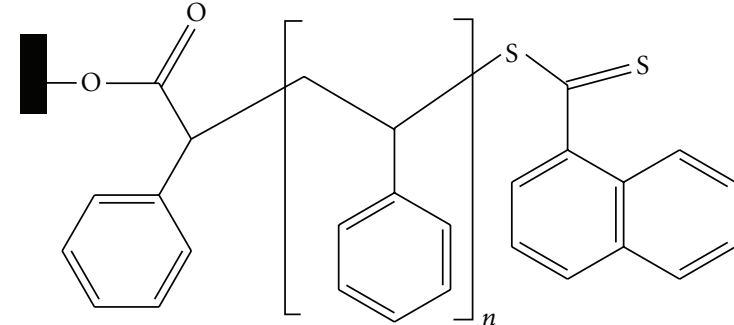

PVA-g-PS

Scheme 1: The synthesis pathway to PVA-g-PS via RAFT process.

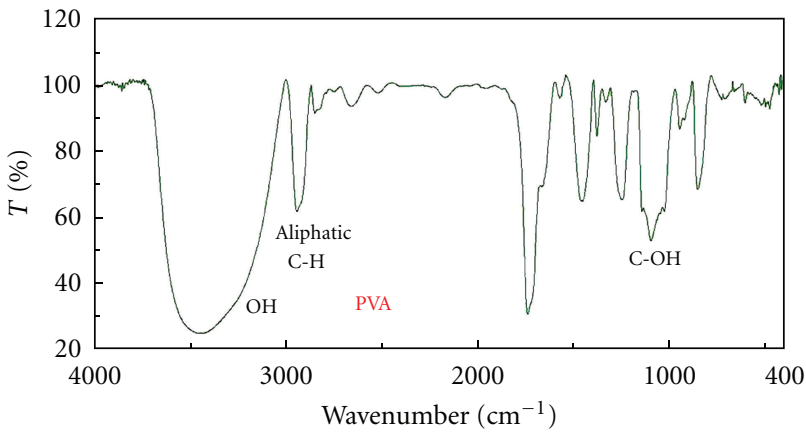

Figure 1: FTIR spectrums of PVA.

chloride according to Scheme 1. By considering the difference in weight and solubility of two compounds, this conversion is somewhat proving. FTIR spectra of this compound show decrease in absorption of $\mathrm{OH}$ groups due to conversion, and, peaks above $3000 \mathrm{~cm}^{-1}$ was for aromatic protons. Also peaks at $1650-1470 \mathrm{~cm}^{-1}$ were related to aromatic ring and peak at $750 \mathrm{~cm}^{-1}$ for $\mathrm{C}-\mathrm{Cl}$ (Figures 1 and 2). ${ }^{1} \mathrm{H}-\mathrm{NMR}$ spectrum of PVA-Cl showed peaks at $7.3 \delta$ for aromatic protons, $6.1 \delta$ for PVA backbone, $5.5 \delta$ for

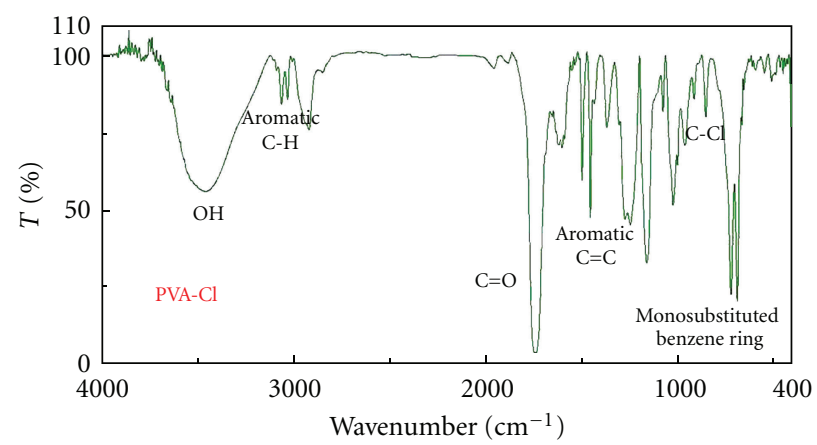

FIgUre 2: FTIR spectrums of PVA-Cl.

unreacted OH groups, $4.8 \delta$ for benzylic proton and 2-1 $\delta$ for PVA backbone. (Figure 3).

At the second step, a Grignard reagent was synthesized from 1-bromo naphthalene and reacted with carbon disulfide to afford magnesium bromide naphthalene-1-carbodithioate which was then added to a solution of PVA-Cl in THF to make a PVA-RAFT agent (Scheme 1). The disappearance of peak related to $\mathrm{C}-\mathrm{Cl}$ at $750 \mathrm{~cm}^{-1}$, appearance of peaks related to $C-S$ and $C=S$ at $1250-1020 \mathrm{~cm}^{-1}$ and also existence 


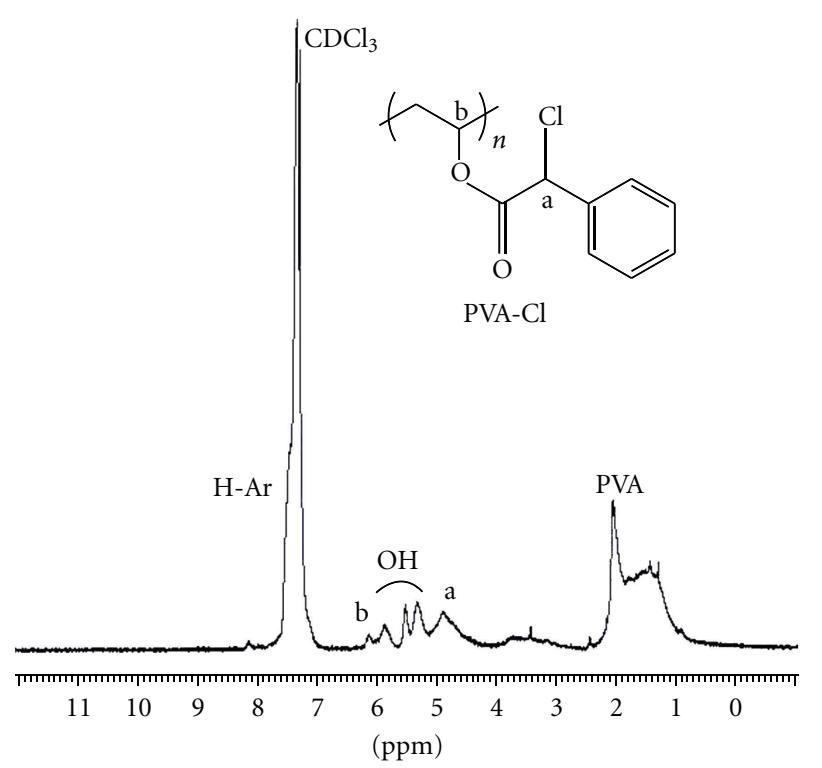

Figure 3: ${ }^{1} \mathrm{H}-\mathrm{NMR}$ spectrum of PVA-Cl.

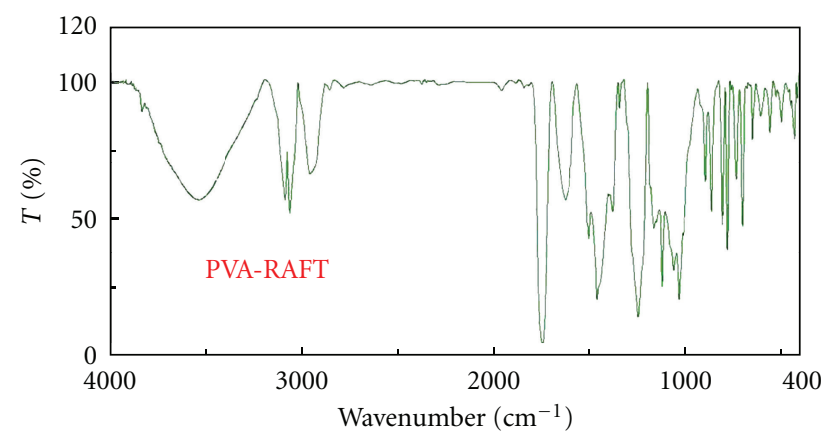

FIgURE 4: FTIR spectrums of PVA-RAFT.

of sharp peaks above $500 \mathrm{~cm}^{-1}$ related to naphthalene group in FTIR spectrum completely confirmed this conversion (Figure 4).

The ${ }^{1} \mathrm{H}$-NMR spectrum of this compound of this compound showed peaks at 8.2-7.1 $\delta$ for aromatic protons, $5.8 \delta$ for PVA backbone, $4.9 \delta$ for unreacted OH groups, $3.9 \delta$ for benzylic proton, and 2.1-1.2 $\delta$ for PVA backbone. (Figure 5).

The CHNS elemental analysis of this compound confirmed formation of thiocarbonyl groups in poly(vinyl alcohol) structure.

The polystyrene was grafted from poly(vinyl alcohol) via RAFT polymerization by using AIBN as initiator.

In order to remove any homo polymer of styrene, the resulted sample was washed with toluene by soxhlet extraction.

The graft ratio $(\mathrm{G}, \mathrm{wt} \%)$ was calculated using

Grafting ratio $(w t \%)=\frac{\text { Weight }_{\text {graft }}-\text { Weight }_{\text {PVA-RAFT }}}{\text { Weight }_{\text {PVA-RAFT }}} \times 100$.

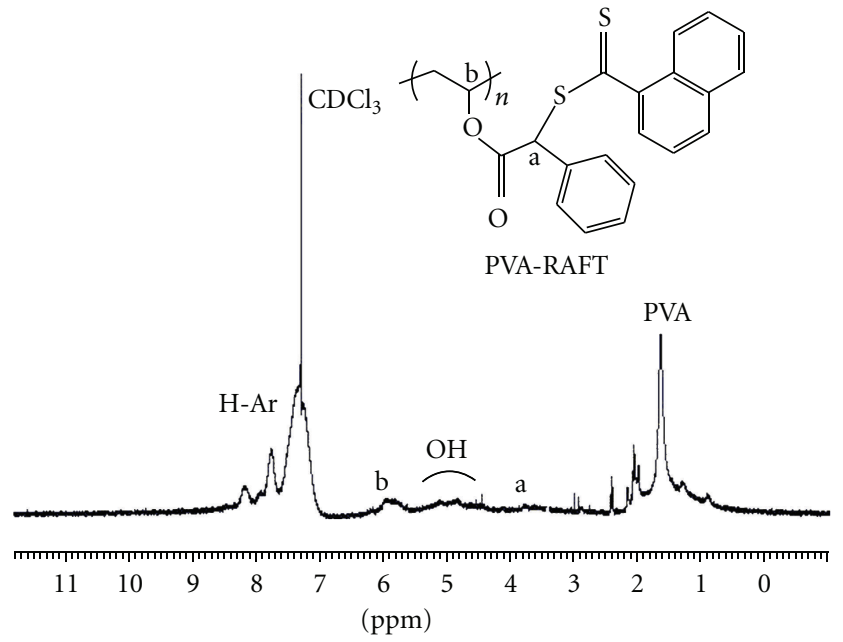

FIgURE 5: ${ }^{1} \mathrm{H}-\mathrm{NMR}$ spectrum of PVA-RAFT.

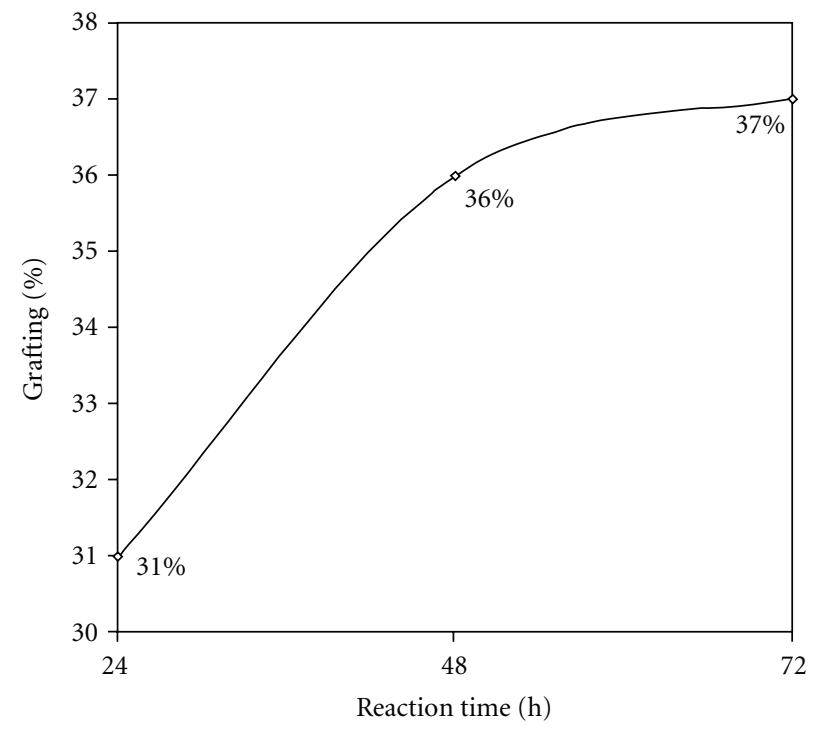

FIGURE 6: Grafting percent versus reaction time.

Here, "weight graft" is the dry weight of PVA-RAFT sample after grafting with poly(styrene) and "weightPVA-RAFT" is the initial weight of PVA-RAFT sample.

To evaluate the increasing the polystyrene grafting percent, first the grafting reaction was done in three different times, $24 \mathrm{~h}, 48 \mathrm{~h}$, and $72 \mathrm{~h}$. As shown in Figure 6, the optimum grafting percent was $36 \%$, which was obtained after $48 \mathrm{~h}$. Next, in constant initiator amount and reaction time of $48 \mathrm{~h}$, the grafting percent was investigated by varying the molar ratio of $[\mathrm{M}]:[\mathrm{PVA}-\mathrm{RAFT}]$ into $250: 1,500: 1$ and $1000: 1$ and as shown in Figure 7, the optimum grafting percent was $36 \%$ in $500: 1$ molar ratio.

The FTIR spectra of PVA-g-PS showed a decrease in $\mathrm{C}=\mathrm{O}$ absorption and increase in aromatic and aliphatic $\mathrm{C}-\mathrm{H}$. Two sharp peaks at $750-650 \mathrm{~cm}^{-1}$ are related to aromatic rings of polystyrene (Figure 8). 


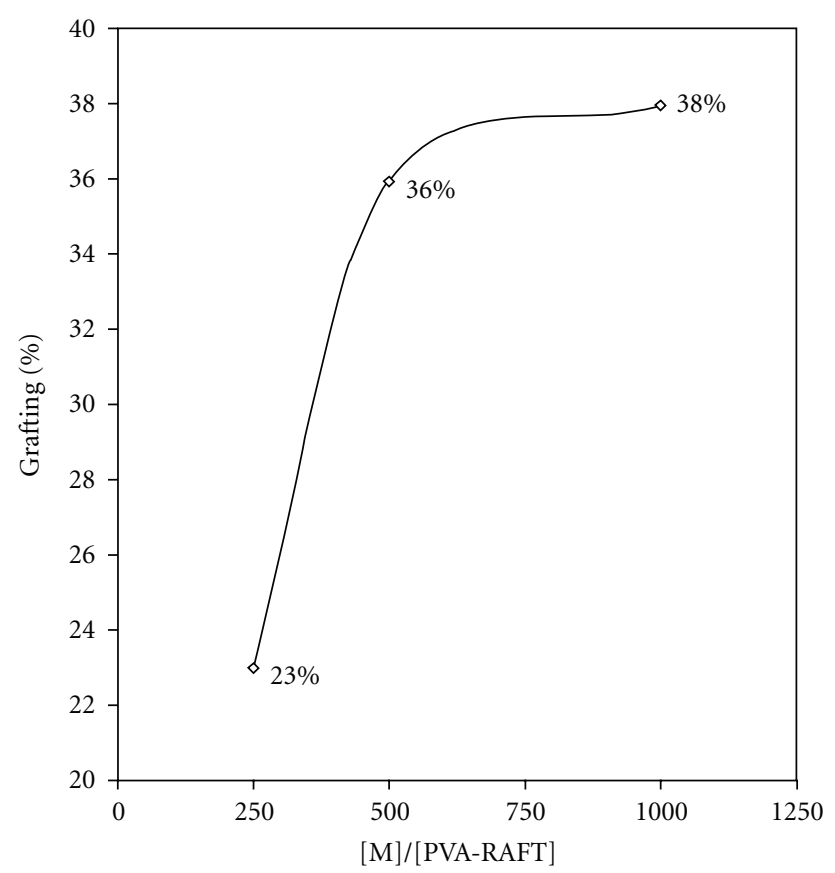

FIGURE 7: Grafting percent versus [M]/[PVA-RAFT] molarratio.

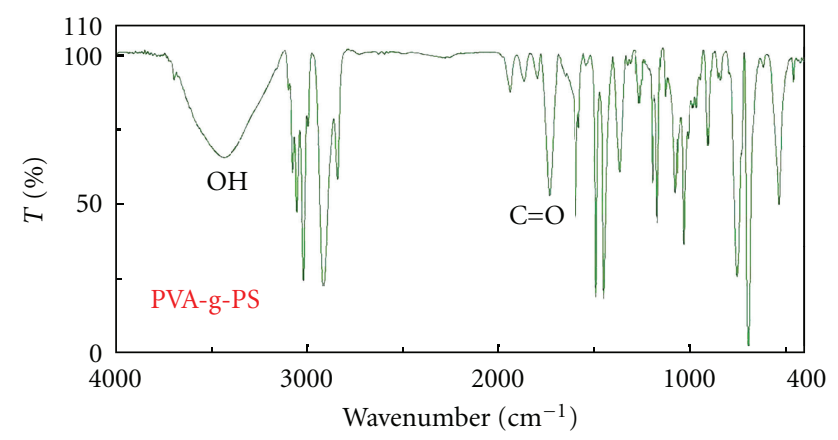

FIgURE 8: FTIR spectrums of PVA-g-PS.

To obtain molecular weight and polydispersity index (PDI) of grafted polystyrene, the compound PVA-g-PS was refluxed under acidic conditions in THF for two weeks. After cleavage of polystyrene chains, a solution in THF was prepared, and its molecular weight was obtained using GPC. $\mathrm{M}_{w}=26000 \mathrm{~g} / \mathrm{mol}, \mathrm{M}_{n}=16000 \mathrm{~g} / \mathrm{mol}, \mathrm{PDI}=1.6$ (Figure 9).

In order to obtain better information about grafting copolymer, XRD analysis of PVA and PVA-g-PS was also investigated. The Peak related to PVA at $2 \theta=19.63^{\circ}$ and The peak related to PVA-g-PS at $2 \theta=19.45^{\circ}$ show that grafting polystyrene to PVA caused increasing chains distance and also reduction of its crystallinity due to reduction of hydrogen bonding between PVA chains. (Figure 10).

Scanning electron microscopy was also used to analyze the morphology of the poly(vinyl alcohol) before and after grafting. SEM micrographs of unmodified PVA and PVA-gPS are shown in Figure 11. It is evident that the modified poly(vinyl alcohol) by grafted polystyrene has different

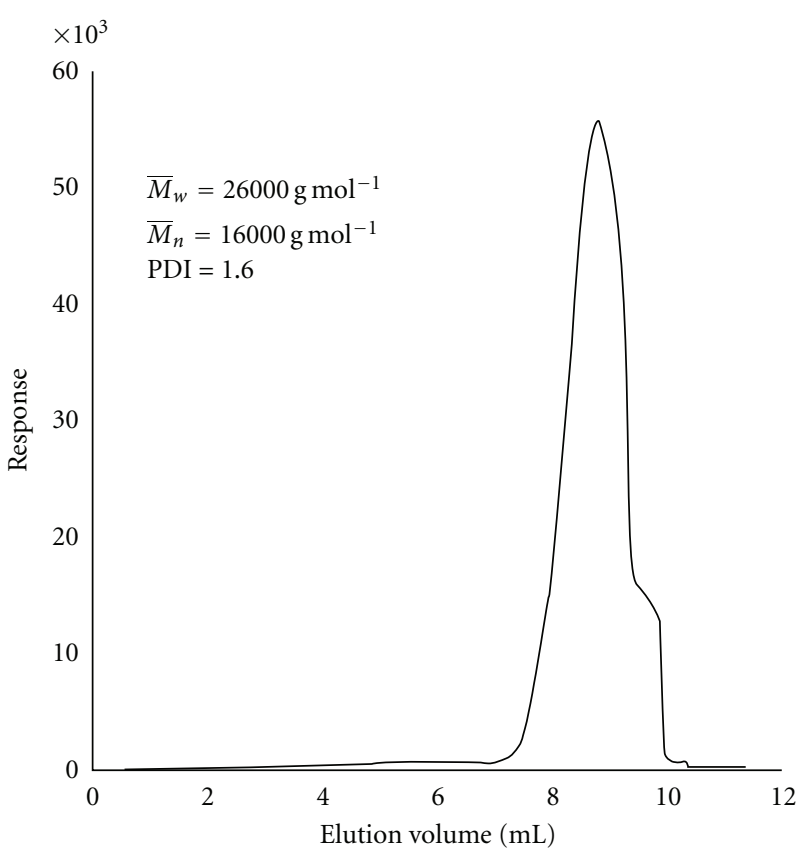

FIGURE 9: GPC graph of PS.

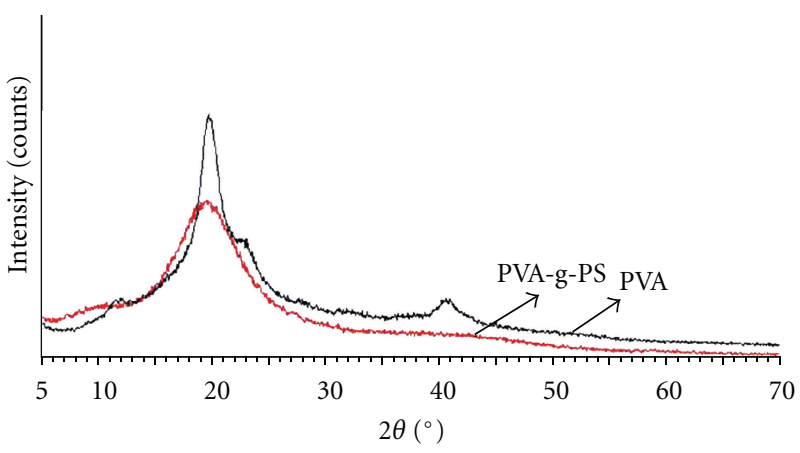

Figure 10: XRD spectra of PVA and PVA-g PS.

structural features compared with the unmodified poly(vinyl alcohol) since the grafting of polystyrene chains occurs mainly at the surface of poly(vinyl alcohol).

Thermal stability of PVA, PVA-RAFT, PVA-g-PS, and PS were investigated by TGA. Figure 12 showed that PS starting to weight loss at $350^{\circ} \mathrm{C}$, while for PVA, this temperature is $240^{\circ} \mathrm{C}$. At the other hand, the percent of remaining polymer at $450{ }^{\circ} \mathrm{C}$ for PS is $0 \%$ while for PVA is near $30 \%$. The higher thermal stability of PS than PVA was because of aromatic groups in PS. This was confirmed for other compounds, PVA-RAFT which was start to weight loss at $300^{\circ} \mathrm{C}$ and PVAg-PS at $310^{\circ} \mathrm{C}$. The grafting technique is increased thermal stability of PVA.

\section{Conclusion}

RAFT is a new method for synthesis of grafted copolymers. According to obtained results, polystyrene was grafted to polyvinyl alcohol under mild condition by using RAFT 


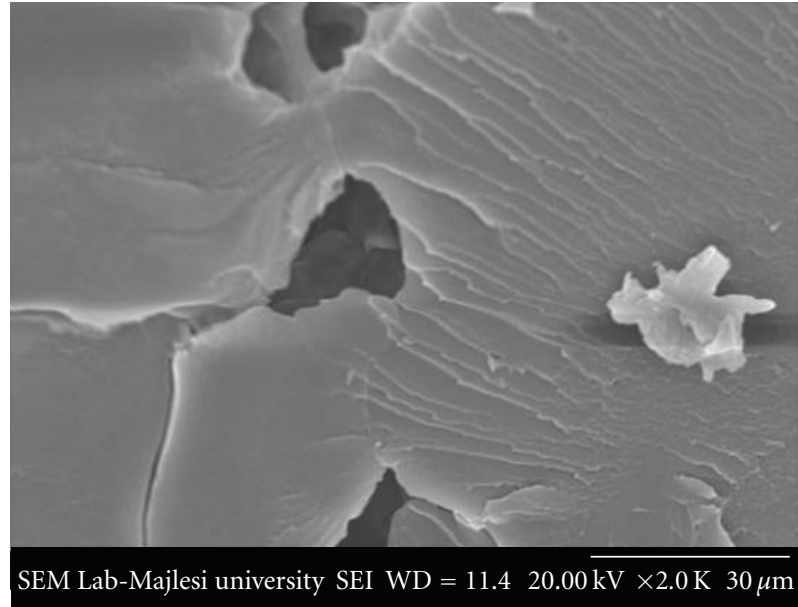

(a)

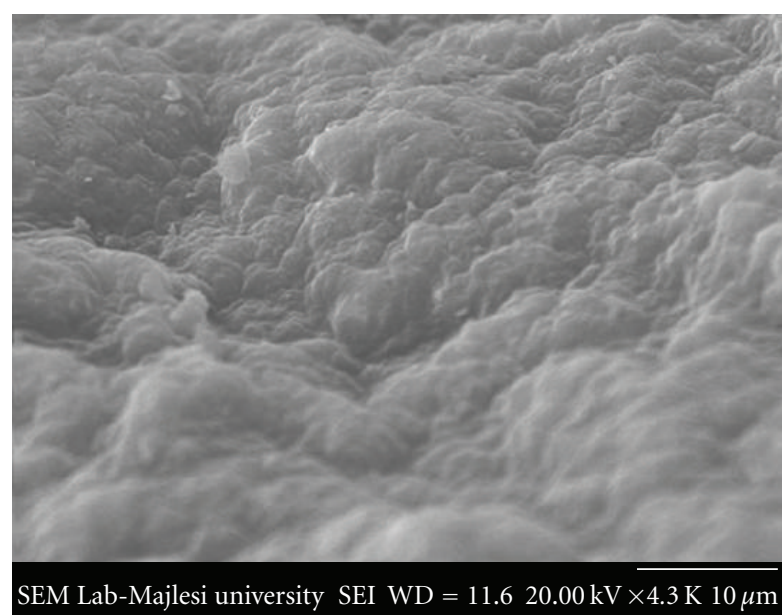

(b)

FIGURE 11: SEM surface image of the (a) unmodified poly(vinyl alcohol) and (b) modified poly(vinyl alcohol) with polystyrene through RAFT process.

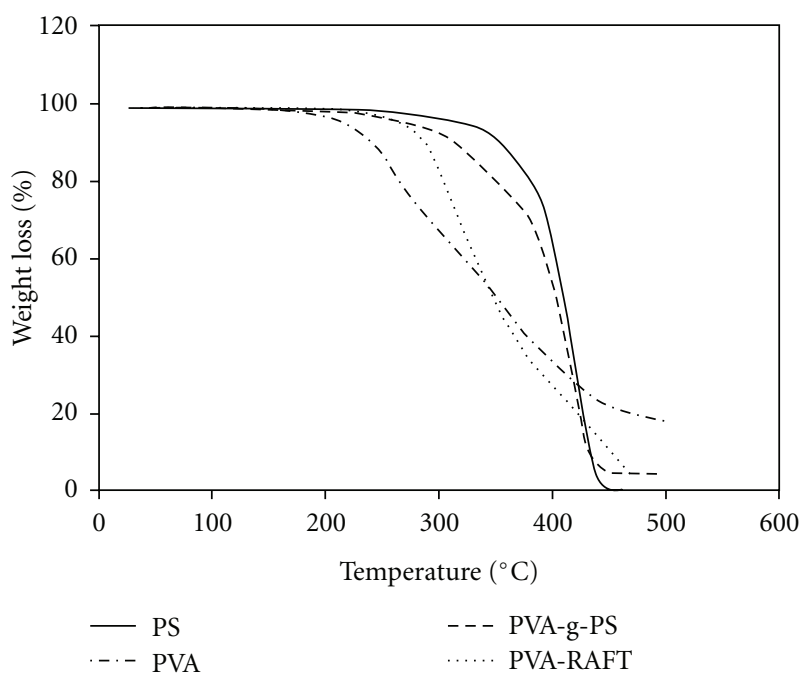

FIGURE 12: Compared TGA thermogram of polymers.

polymerization technique. Grafted copolymer with high percentage polystyrene was obtained, which was characterized and investigated by FTIR, XRD and TGA. The grafted polystyrene was hydrolyzed from copolymer and showed narrow molecular weight distribution obtained with GPC.

\section{Acknowledgments}

The authors thank University of Isfahan providing facilities for this work and Central Laboratory of University of Isfahan for FTIR, CHN, ${ }^{1} \mathrm{HNMR}, \mathrm{GPC}$, and XRD analysis.

\section{References}

[1] J. C. Salomone, Polymeric Materials Encyclopedia, CRC Press, Boca Raton, Fla, USA, 1996.

[2] J. A. Miller, Science News, vol. 112, p. 154, 1977.
[3] M. Pines, "Modern bioengineers reinvent human anatomy with spare parts," Smithsonian, vol. 9, no. 8, pp. 50-57, 1978.

[4] C. Shao, H. Y. Kim, and J. Gong, "Fiber mats of poly(vinyl alcohol)/silica composite via electrospinning," Materials Letters, vol. 57, p. 1579, 2003.

[5] U. Westedt, M. Wittmar, M. Hellwig et al., "Paclitaxel releasing films consisting of poly(vinyl alcohol)-graft- poly(lactide-coglycolide) and their potential as biodegradable stent coatings," Journal of Controlled Release, vol. 111, no. 1-2, pp. 235-246, 2006.

[6] D. A. Ossipov, S. Piskounova, and J. Hilborn, "Poly(vinyl alcohol) cross-linkers for in vivo injectable hydrogels," Macromolecules, vol. 41, no. 11, pp. 3971-3982, 2008.

[7] D. A. Ossipov and J. Hilborn, "Poly(vinyl alcohol)-based hydrogels formed by "click chemistry"," Macromolecules, vol. 39, no. 5, pp. 1709-1718, 2006.

[8] B. N. Gacal, B. Koz, B. Gacal, B. Kiskan, M. Erdogan, and Y. Yagci, "Pyrene functional poly(vinyl alcohol) by "click" chemistry," Journal of Polymer Science, vol. 47, no. 5, pp. 13171326, 2009.

[9] C. J. Hawker, A. W. Bosman, and E. Harth, "New polymer synthesis by nitroxide mediated living radical polymerizations," Chemical Reviews, vol. 101, no. 12, pp. 3661-3688, 2001.

[10] J. Xia, X. Zhang, and K. Matyjaszewski, "Synthesis of starshaped polystyrene by atom transfer radical polymerization using an 'arm first' approach," Macromolecules, vol. 32, no. 13, pp. 4482-4484, 1999.

[11] T. P. Le et al., The Patent Cooperation Treaty International Application, 1998.

[12] J. Chiefari, Y. K. Chong, F. Ercole et al., "Living free-radical polymerization by reversible addition - Fragmentation chain transfer: the RAFT process," Macromolecules, vol. 31, no. 16, pp. 5559-5562, 1998.

[13] G. Moad, E. Rizzardo, and S. H. Thang, "Living radical polymerization by the RAFT process," Australian Journal of Chemistry, vol. 58, no. 6, pp. 379-410, 2005.

[14] J. F. Quinn, R. P. Chaplin, and T. P. Davis, "Facile synthesis of comb, star, and graft polymers via reversible additionfragmentation chain transfer (RAFT) polymerization," Journal of Polymer Science, vol. 40, no. 17, pp. 2956-2966, 2002. 
[15] M. Barsbay, O. Güven, M. H. Stenzel, T. P. Davis, C. BarnerKowollik, and L. Barner, "Verification of controlled grafting of styrene from cellulose via radiation-induced RAFT polymerization," Macromolecules, vol. 40, no. 20, pp. 7140-7147, 2007.

[16] A. B. Lowe and C. L. McCormick, "Homogeneous controlled free radical polymerization in aqueous media," Australian Journal of Chemistry, vol. 55, pp. 367-379, 2002.

[17] L. Bai and C. Wang, "Graft copolymerization of styrene onto poly (vinyl alcohol)initiated by potassium diperiodatocuprate," Iranian Polymer Journal, vol. 18, pp. 847-855, 2009.

[18] S. Nigam, R. Bandopadhyay, A. Joshi, and A. Kumar, "Grafting of polystyrene on to poly(vinyl alcohol) (PVA) by a PVA$\mathrm{CuCl} 2$ complex initiating system in an aqueous medium," Polymer, vol. 34, no. 20, pp. 4213-4220, 1993.

[19] Y. Tezuka and A. Araki, "Synthesis of poly(vinyl alcohol)graft-polystyrene," Die Makromoleculare Chemie, vol. 194, pp. 2827-2837, 1993.

[20] R. Saito, S. I. Okamura, and K. Ishizu, "Synthesis of poly(vinyl alcohol) core-polystyrene shell type microspheres," Polymer, vol. 36, no. 23, pp. 4515-4520, 1995.

[21] U. Akira, N. Yoichi, and N. Noboru, Science and Industry, vol. 78, pp. 127-135, 2004.

[22] A. Suzuki, Y. Matsuda, T. Masuda, K. Kikuchi, and T. Okaya, "Effect of additives on the initial stage of emulsion polymerization of styrene (St) using poly(vinyl alcohol) as a protective colloid," Colloid and Polymer Science, vol. 285, no. 2, pp. 193201, 2006. 

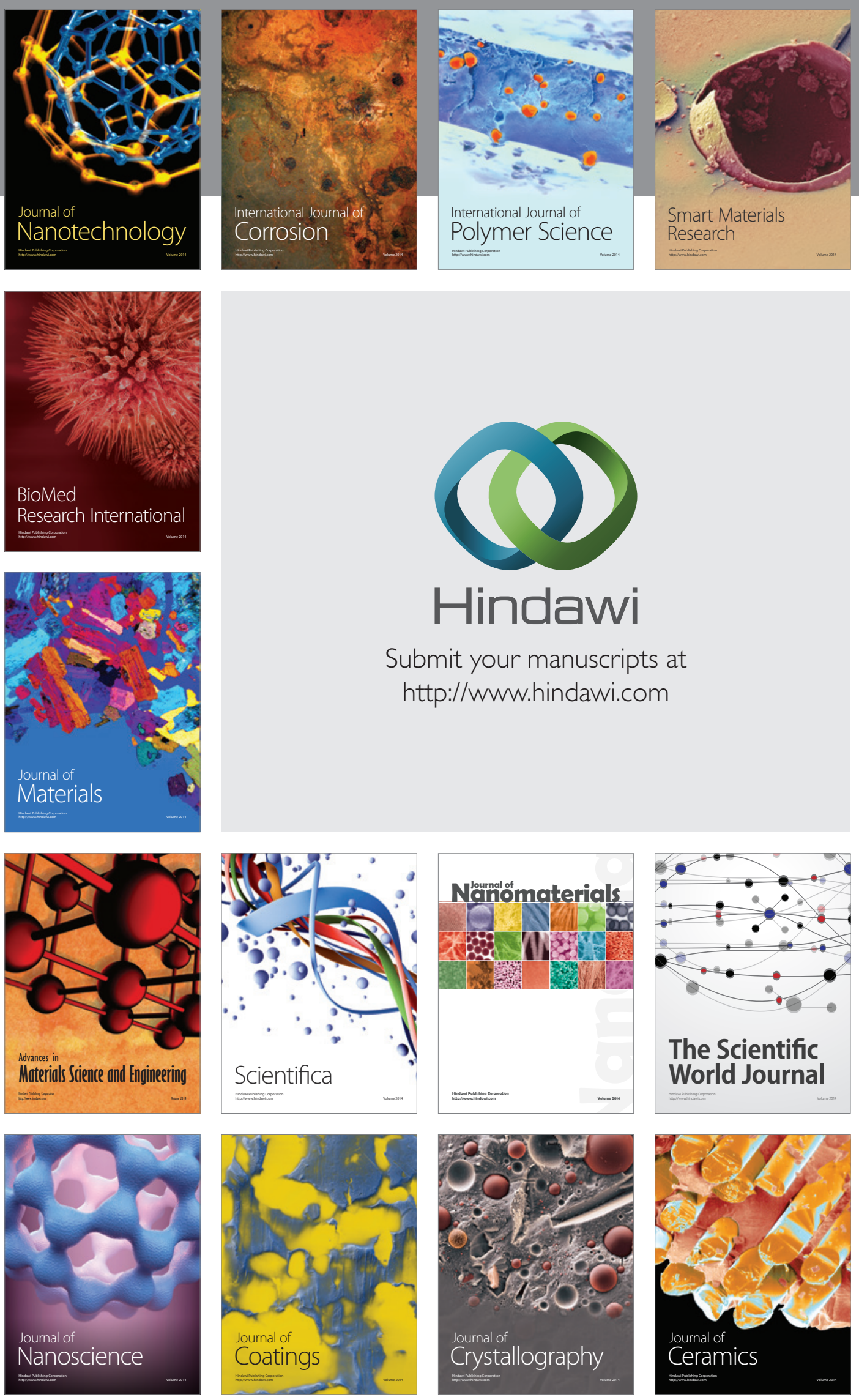

The Scientific World Journal

Submit your manuscripts at

http://www.hindawi.com

\section{World Journal}

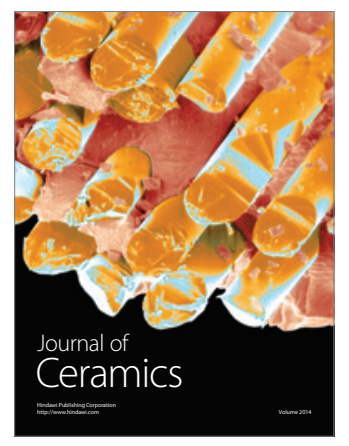

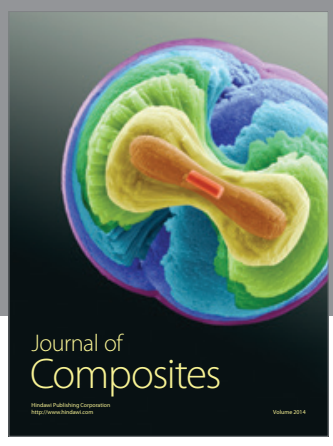
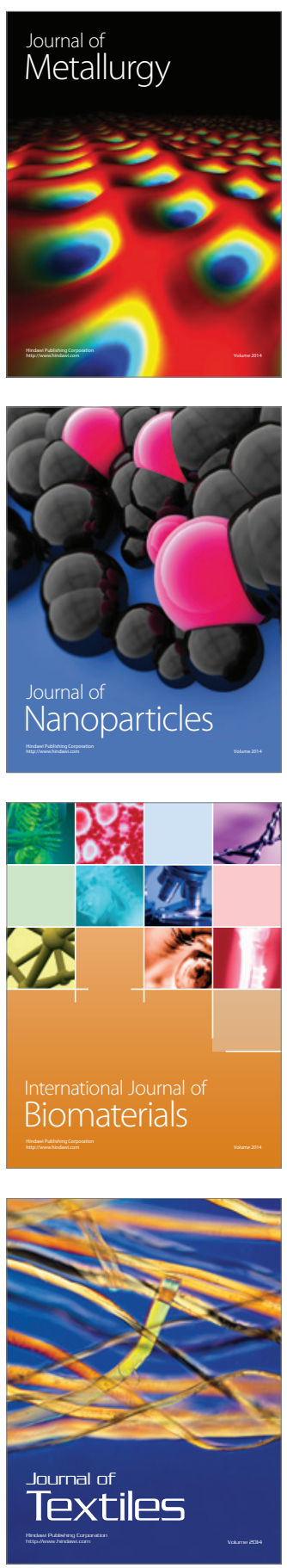